\title{
Review on Factors which Affect Coffee (Coffea Arabica L.) Quality in South Western, Ethiopia
}

\author{
Habtamu Deribe * \\ Department of Plant Science College of Agriculture and Natural Resource, Bonga university Bonga \\ Ethiopia \\ *Corresponding Authors: Habtamu Deribe, Department of Plant Science College of Agriculture and \\ Natural Resource, Bonga university Bonga Ethiopia
}

\begin{abstract}
Coffee is the most important crop in the national economy of Ethiopia and the leading export commodity. Ethiopia is well known not only for being the home of Arabica coffee, but also for it is very fine quality coffee acclaimed for its aroma and flavor characteristics. Coffee quality is of critical importance to the coffee industry. Cup quality is a complex characteristic which depends on a series of factors such as the species or variety (genetic factors), environmental conditions (ecological factors), agronomical practices (cultivation factors), processing systems (postharvest factors), storage conditions, industrial processing, preparation of the beverage and taste of the consumer. However, in Ethiopia the quality of coffee produced by farmers has been deteriorating from time to time. Moreover, factors that determine coffee quality are genotypes, climatic conditions, and soil characteristics of the area, agronomic practices, harvesting methods and timing, postharvest processing techniques, grading, packing, storage conditions and transporting, all contribute either exaltation or deterioration of coffee.
\end{abstract}

Keywords: coffee, quality, factors

\section{INTRODUCTION}

Coffee is a perennial field crop which belongs to the genus Coffea in the Rubiaceae family, and is mostly grown in the tropical and subtropical regions (Berthaud and Charrier, 1988). Almost all the coff ee species are diploid $(2 \mathrm{n}=2 \mathrm{x}=22)$ and generally self-incompatible except $\mathrm{C}$. Arabica which is a natural allotetraploid $(2 \mathrm{n}=4 \mathrm{x}=44)$ self-fertile species(Charrier and Berthaud, 1985). About 124 species of the genus Coffea have been identified so far (Davis et al., 2012). Coffea Arabica is known to be one of the most important beverages in the world and is a very important source of foreign exchange for many countries (Labouisse et al., 2008). In the consumer market, C. Arabica is preferred for its beverage quality, aromatic characteristics, and low-caff eine content compared to Robusta, which is characterized by a stronger bitterness, and higher-caff eine content. Arabica contributes towards $65 \%$ of global coff ee production (L'ecolier et al., 2009).

Ethiopia had been the origin of coffee since coffee plant was initially found and cultivated in the Kaffa province (Bonga, Makira) of Ethiopia (UNCTAD/WTO, 2002). Ethiopia is the primary center of origin and center of genetic diversity of Coffea Arabica L. and the existence of such genetic diversity provides immense opportunity for coffee improvement (Fikadu et al., 2008).

Ethiopia is the primary center of origin and center of genetic diversity of Coffea Arabica L. and the existence of such genetic diversity provides immense opportunity for coffee improvement (Fikadu et al., 2008).Ethiopia is the home and cradle of biodiversity of Arabica coffee seeds and also it is the center for origin, diversification, and dissemination of the coffee plant (Bayetta, 2001). According to CSA, (2017), the estimated area of land covered by coffee in Ethiopia is about 700474.69 ha, whereas the estimated annual national production of clean coffee is about 469091.12 tons with average productivity of $669.6 \mathrm{~kg} \mathrm{ha}^{-1}$.

Ethiopia remains the largest producer of coffee in Africa and is the fifth largest coffee producer in the world next to Brazil, Vietnam, Colombia and Indonesia, contributing to about $4.2 \%$ of the total world coffee production (ICO, 2016). Coffee is one of the leading traded commodities on the global market in both volume and value (Zewdu, 2016). The world coffee production is estimated at approximately 8.75 million tons which are accounted for about 23.4 billion US dollar in export value in 2013. 
Arabica coffee is cultivated in $85 \%$ of the coffee producing countries, and the American Continent accounts for approximately 60-70\% of the world coffee production (ICO, 2014). The coffee sector employs more than 100 million people in different parts of the World (Petit, 2007). In the global market, coffee is a strategic crop since it is a primary source of livelihood for many farmers (ITC, 2011).

In Ethiopia, the coffee is produced within specific agro-ecological zones, in several geographical and political boundaries. The main coffee-production areas of Ethiopia are the south-west and south-east, with modest and minor production in the north part of the country. According to Davis et al., (2017), stated that "coffee production had been negatively influenced by changes in climate". Coffee produced in different production systems that include forest, semi-forest, garden, and a modern plantation. There are differences of opinion on the amount of farm size for coffee production area by smallholders. More than 90 percent of coffee produced in the country comes from smallholder farmers, and the rest 10 percent is from medium and large scale producers (USDA, 2016). The majority of production is on the small garden field and on average less than 2 hectares with yields remaining low at around $0.7-0.8$ metric tons per hectare (USDA, 2016). The production is mainly by smallholder farmers on average reported about 0.67 ha.

Major factors such as predominant use of unimproved local coffee landraces, as well as conventional husbandry and processing practices, which in turn seriously hampers the overall national coffee production and productivity of the smallholder coffee farmers in the country (Taye, 2010). Ethiopia exports its coffee based on their areas of origin (type), which are known for their own distinct quality and agronomic characters (MoARD, 2008). Musebe et al. (2007) reported that coffee quality is determined by $40 \%$ in the field, $40 \%$ at postharvest primary processing and $20 \%$ at secondary processing and handling practices. However, there are a lot of factors which deteriorate the quality of coffee produced in the areas. This is mainly due to poor management of agronomic practices, poor post-harvest management, shortages of processing technologies (wet $\&$ dry process) and storage practices. Therefore, the gap of those challenges can affect marketing linkages of coffee in national and international levels. Therefore, the main objective of this review is to review factors which affect quality coffee productin Southwestern Ethiopia.

\subsection{Coffee Production in Ethiopia}

Coffee is Ethiopia's largest export crop, (Petit, 2007). Ethiopia produces only Arabica coffee which is considered as superior to Robusta coffee due to its fine aroma, strong body, and pleasant acidity (Zewdu, 2016). The country produces premium quality Arabica coffee in Africa and is the third largest producer in the world (ICO, 2014). A quarter of the total population of Ethiopia is directly or indirectly dependent on the income they generate from growing coffee for their livelihood (Zewdu,2016). The coffee production sector in Ethiopia is being supported by both Regional and Federal Governments (Berhanu, 2017). The country has enormous potential to become the leading coffee producer in the world, (Gole, 2015), primarily because of quality characteristics of the coffee (Alemseged, 2012). The Ethiopian coffee is characterized by its rich in aroma and flavor makes it desirable for blending with coffee from other countries. The change in consumer behavior and the increasing consumption of high-quality coffee is an opportunity for the coffee producing countries like Ethiopia. Improving coffee quality is a key prospect for increasing coffee exports and may be a good strategy to get better prices for the coffee (Kassaye, 2017). According to Herhaus (2014), Ethiopia is known for producing the finest Arabica coffee to the world market.

\subsection{Coffee Quality}

Quality can be a section of coffee comes from a combination of the botanical variety, topographical conditions, weather conditions, and the management given during growing spell, harvesting, storage, preparation for export and transport. They comprise intervention by human beings, whose motivation is the main factor in the determination of the final quality of a part of green coffee. Several factors contribute to the quality of the coffee that producers and environment widely handle them (ITC, 2011). According to Richard et al., 2007 the quality of coffee is impacted by $40 \%$ at the pre-harvest stage, $40 \%$ at post-harvest practices stage and $20 \%$ at export handling. In recent years, different coffee producing countries have tremendously expanded their production and export volume (Behailu et al., 2008). According to the current context of overproduction and low prices of the coffee market, improvement and valorization of coffee quality could provide the coffee chain with a new impetus (Leroy et al., 2006). At the farmer level, coffee quality is a combination of production level, price and 
easiness of culture; at the exporter or importer level, coffee quality is linked to bean size, lack of defects and regularity of provision, tonnage available, physical characteristics and price; at the roaster level, coffee quality depends on moisture content, stability of the characteristics, origin, price, biochemical compounds and organoleptic quality (Leroy et al., 2006).

Production and supply of coffee with excellent quality seems more crucial than ever before for coffee exporting countries. Consequently, some countries consider assessment of coffee quality as important as disease resistance and productivity in their coffee variety development program (ITC, 2004). In view of the present situation, making effort to overcome challenges and threats only through expansion of production does not seem visible for countries like Ethiopia. Thus, it has been repeatedly mentioned at various forum that providing good quality coffee is the only way out and viable option to get into the world market and to remain competitive (Behailuet al., 2008). Coffee is the most important crop in the national economy of Ethiopia and the leading export commodity. Ethiopia is well known not only for being the home of Arabica coffee, but also for it is very fine quality coffee acclaimed for its aroma and flavor characteristics.

The coffee types that are distinguished for such unique characteristics include Sidamo, YirgaChefe, Harerge, Gimbi and Limu types (Workafes and Kassu, 2000). However, coffee produced in some parts of Ethiopia, especially from Harrar, and Yirgachefe, is always sold at a premium price both at domestic and international coffee markets because of its distinctive fine quality (Chifra et al., 1998; ITC, 2002) and appropriate processing approach. On the other hand, sun dried Jimma coffee is one of the lowest priced coffees in the international market due to inappropriate processing as opposed to Limmu washed grade 2 which, fetches better premium price though it is produced in the same agroecological zone (Desse, 2008). Furthermore, Desse (2008) reported that although the inherent flavor of Jimma coffee is pleasantly winy, some of the common cup defects are earthy, musty with secondary cup defects of taints in the liquor, which are mainly due to post harvest management problems.

According to the International Organization for Standardization (ISO) (2000), Quality is described as "the ability of a set of inherent characteristics of a product, system or process to fulfill requirement of customers and other interested parties". These inherent characteristics can also be called "attributes". For coffee, the definition of quality and the attributes considered have probably evolved through the centuries. But nowadays, this definition varies along the production-to-consumer chain (Leroy et al., 2006). i.e.; at the farmer level, coffee quality is a combination of production level, price and easiness of culture; at the exporter or importer level, coffee quality is linked to bean size, lack of defects and regularity of provision, tonnage available, physical characteristics and price; at the roaster level, coffee quality depends on moisture content, stability of the characteristics, origin, price, biochemical compounds and organoleptic quality (Leroy et al., 2006). It should be noted that each consumer market or country may define its own organoleptic qualities; at the consumer level: coffee quality deals with price, taste and flavor, effects on health and alertness, geographical origin, environmental and sociological aspects (organic coffee, fair trade, etc (ISO, 2000).

More specifically, ISO (2004a) defined a standard for green coffee quality (ISO 9116 standard) as, it requires several pieces of information, like the geographical and botanic origins of the coffee, the harvest year, the moisture content, the total defects, the proportion of insect-damaged beans and the bean size. These ISO standards define methods of measurements for several of these qualities such as, defects, moisture content, bean size, some chemical compounds and preparation of samples to perform cup tasting.

According to the definition of quality and standards authority of Ethiopia (QSAE) (2000) a quality is conformance with requirements or fitness for use in which the parties involved in the industry (customer, processor, supplier, etc) should agree on the requirements and the requirements should be clear to all stake holders involved in the process. On the other hand, Coffee Quality control and auction Center was established with a key objective of maintaining coffee quality control, which in turn facilitates the coffee marketing system to be standard based, and for the betterment /proper functioning of the long coffee supply chain of Ethiopia (Endale, 2008). Coffee has only one value to give the consumer pleasure and satisfaction through flavor, aroma and desirable physiological and psychological effects (Yigzaw, 2005). Therefore coffee quality, especially liquor or cup quality, determines both the relative price and usefulness of a given quantity of coffee (Agwanda et al., 2003). Cup quality, often referred to as drinking quality or liquor quality, is an important attribute of coffee 
(Muschler, 2001; Agwanda et al., 2003) and acts as yardstick for price determination (Agwanda et al., 2003).

\section{FACTORS AFFECTING COFFEE QUALity}

Accordingly, different authors were reported as there are different activities which affect coffee quality in many ways. Therefore, measurements that should be undertaken are briefly discussed below. Cup quality is a complex characteristic which depends on a series of factors such as the species or variety (genetic factors), environmental conditions (ecological factors), agronomical practices (cultivation factors), processing systems (post- harvest factors), storage conditions, industrial processing, preparation of the beverage and taste of the consumer (Moreno et al., 1995). Coffee quality is of critical importance to the coffee industry. Quality coffee is a product that has desirable characteristics such as clean raw and roasted appearance, attractive aroma and good cup taste (Behailuet al., 2008). However, in Ethiopia the quality of coffee produced by farmers has been deteriorating from time to time. Moreover, factors that determine coffee quality are genotypes, climatic conditions, and soil characteristics of the area, agronomic practices, harvesting methods and timing, post-harvest processing techniques, grading, packing, storage conditions and transporting, all contribute either exaltation or deterioration of coffee (Behailuet al.,2008). Similarly, Damanu (2008), reported coffee quality as a combination of the botanical variety, topographical conditions, and climatic conditions and the care taken during growing, harvesting, storage, exports preparation and transport. According to the author botanical variety and topographical conditions are constant and therefore dominate the inherent characters of a coffee where as other factors except climatic conditions can be influenced by human being and are a key factor in determination of the end quality of a green coffee. Furthermore, inadequate systems of harvesting, processing, storage and transportation are responsible for the wide spread failure to maintain the inherent quality of coffee produced in Ethiopia (Alemayehu et al., 2008).

\subsection{Climatic and Soil Factors}

The environment has also a strong influence on coffee quality (Decasy et al., 2003). Rainfall and sunshine distributions have a strong influence on flowering, bean expansion, and ripening (Harding et al., 1987). Altitude, daily temperature fluctuations, amount and distribution of rainfall and the physical and chemical characteristics of the soil are very important factors. Climate, altitude, and shade play an important role through temperature, availability of light and water during the ripening period (Decasy et al., 2003).

The slowed-down ripening process of coffee berries at higher elevations (lower air temperatures), or under shading, allows more time for complete bean filling (Vaastet al., 2006), yielding beans that are denser and far more intense in flavor than their neighbors grown at lower altitudes (or under full sunlight). The slower maturation process should therefore play a central role in determining high cup quality, possibly by guaranteeing the full manifestation of all biochemical steps required for the development of the beverage quality (Silva et al., 2005). For instance, chlorogenic acids and fat content have been found to increase with elevation in C. Arabica (Bertrand et al., 2006). Besides the beneficial effect of longer duration of the bean-filling period, a larger leaf area-to-fruit ratio (better bean-filling capacity) may also be linked to superior cup quality (Vaast et al.,2006).

The role of soil types has been well studied and it is generally admitted that the most acidic coffee quality is grown on rich volcanic soils (Harding et al., 1987). The perceived acidity of coffee brews has always been recognized as an important attribute of coffee quality. Acidity is typically a highly valued quality especially in Central American and some East African coffees (Yigzaw, 2005). Sourness, however, is an extreme of acidity and can be considered as defect. Acidity has been correlated with coffees grown at very high altitudes and in mineral rich volcanic soils. On top of this Yigzaw (2005) reported that if other factors are kept constant, better quality coffee can be found at higher altitudes, while low land coffee were found to be somewhat bland, with considerable body.

Moreover, coffee from high altitude areas was more acidic, with better aroma and flavor.

Woelore (1993) reported that for Ethiopian conditions an underwater fermentation technique and the time for fermentation for different agro-ecologies are recommended. According to the author mucilage degradation washed at the first, second, third, or after the third day from pulping in the altitudinal range $1200 \mathrm{~m}$ and below, $1200-15000 \mathrm{~m}, 1500-1800 \mathrm{~m}$ and above $1800 \mathrm{~m}$, respectively, for varying fermentation practices. Woelore (1995) reported that factors such as total rainfall, relative 
humidity, maximum-minimum temperatures with effect on water vapor content of the air and storage duration, greatly influence storability and quality of stored parchment coffee. Periods of prolonged drought may also result in lower quality beans (Wintgens, 2004). Most of the coffee tasters agree now that there is very little or no difference in flavor at all between the Arabica pure breeds cultivated under similar agro-climatic conditions (Wintgens, 2004).

\subsection{Pre-Harvest and Harvest Factors}

Yigzaw (2005) reported that in South America, coffee grown with heavy application of nitrogen fertilizer had poorer, lighter and thinner quality than that from unfertilized fields.

An excess of nitrogen increase the caffeine content, resulting in a more bitter taste of the brew. The caffeine and chlorogenic acid contents of the beans are not affected by the levels of phosphorus, calcium, potassium and magnesium in the soil (Wintgens, 2004). A lack of zinc will lead to the production of small light grey-colored beans, which will produce poor liquor (Wintgens, 2004). On the other hand, magnesium deficiency had an adverse effect on cup quality (Mitchell, 1988). High concentration of calcium $(>0.11 \%)$ and potassium $(>1.75 \%)$ in the beans is associated with a bitter and "hard" taste (Wintgens, 2004). Taye (1998) reported the use of decomposed coffee husk at a rate of 10 ton ha -1 ( $4 \mathrm{~kg}$ tree -1 on dry weight basis) was found to be superior in terms of yield performance of coffee trees. A significant improvement in growth and yield of mature coffees was reported in response to coffee pulp and husk compost application (Chane, 1999).

On the other hand, there is no correlation between the phosphorus content and the physical and organoleptic quality of the bean (Wintgens, 2004) .On the contrary, repeated application of elephant grass or livestock manure resulted in an increased percentage of undesirable brown-colored bean and, thus, poor roasting characteristics. This effect was associated with a magnesium deficiency induced by the high potassium content of elephant grass as well as high concentration of potassium and calcium in manure (Wintgens, 2004). Good growth conditions (weed control, appropriate planting density and pruning) usually have a positive effect on bean size and flavor (Wintgens, 2004). The relationship between crop management and total coffee quality, however, has not yet been investigated in detail.

Pests and diseases attacks can affect the cherries directly or cause them to deteriorate by debilitating the plants, which will then produce immature or damaged fruits. Disease and insect attack (such as leaf miner and mites) may also result in lower quality beans (Wintgens, 2004). For instance, as reported by Wintgens (2004) the coffee berry borer Hypothenemushampii feeds and reproduces inside the coffee beans and causes their quality to deteriorate. The antestia sting bug as a vector of microorganisms damages the bean and causes a bitter flavor. Similarly, the fly Ceratitiscapitata feeds on the mucilage and the cherry becomes infected with micro-organisms; the secondary bacterial infection causes a distinct potato flavor. OTA (Ochratoxin A) is a form of mycotoxin, produced as a metabolic product of Aspergillusochraceus, A. carbonarius and strains of A. nigerreported to exist on coffee dried on bare ground (Eshetu and Girma, 2008). Carvalho (1988) reported that shade trees did not improve cup quality. On the contrary, Muschler (2001) indicated that shade improved the appearance of green and roasted coffee beans as well as the acidity and body of the brew, especially for those produced in suboptimal (low altitude) coffee production zones, by promoting slower and balanced filling and uniform ripening of berries. Furthermore, Yemane-Berhan (1998) observed that shade increased sugar concentration, which is an important factor for creating the aroma of coffee.

Accordingly, Yigzaw (2005) reported that samples from young trees are likely to be mild and thin, but fine in flavor. Samples from old trees produce strong taste and a harsh characteristic brew. Medium aged trees, 15 to 20 years old, bear beans with good flavor as well as acidity and body (Yigzaw, 2005). According to the results of studies by (Bertrand et al., 2006; Vaastet al., 2006), tree physiology, plant age, and period of picking all interact to produce the final characteristics of the product. Indeed it was found that tree age, location of the fruits within the tree, and fruits-to-leaves ratio had a strong influence on the chemical content of green beans.

Maturation also has a strong influence on coffee quality. The main factor affecting natural coffee quality is harvesting method. It is widely agreed that traditional hand-picking and husbandry labor, as opposed to mechanical harvest, produce the best quality green coffee by decreasing the percentage of defects in coffee batches. Bertrand et al. (2006) observed that yellow or green cherries picked at the end of the picking season contain beans with a higher maturity level than red cherries of C. canephor picked at the start of the picking season. This can be seen in bean size, chemical contents, and cup 
quality. On the other hand, for C. Arabica in Costa Rica, early picking of red cherries gives the best coffee (Bertrand et al., 2006). On the other hand, Endale et al. (2008) pointed out that low caffeine content were found in bean harvested at immature stage (unripe) and in over-ripe coffee beans with conventional analysis using high performance liquid chromatography (HPLC). According to their findings this could be associated with slow metabolism of caffeine and its biodegradation at immature and over-ripe stages of fruit development, respectively.

\subsection{Post-Harvest Factors}

Depending on the post-harvest processes, significant effects on coffee quality can be observed (Barel and Jacquet, 1994). Processing is a very important activity in coffee production and plays a crucial role in quality determination (Mburu, 1999). Coffee is either processed by the wet or dry methods, which vary in complexity and expected quality of the coffee (Wrigley, 1988). Both sun-drying as well as wet-processing methods are operated in Ethiopia, which accounts for $70 \%$ and $30 \%$ of coffee produced in the country, respectively (Jacquet et al., 2008).

According to Clifford (1985) wet processed Arabica is aromatic with fine acidity and some astringency, while dry processed Arabica is less aromatic and less acidic but with greater body. The perceived acidity of washed coffees is also significantly higher than the acidity found in naturally (dry) processed coffees. This is likely due to an increase in the body of naturally processed coffees relative to wet processed coffees since body masks the coffee's acidity (Yigzaw, 2005). Selmar et al. (2001) reported that sensory evaluation of the roast coffees revealed that the dry and washed coffees could be distinguished with high significance (11 of 11 panel members). As their report the differences in quality of differently processed coffees of similar original material is due to the process taking place in the beans during processing.

In the majority of the study area coffee is prepared using a dry processing (natural sundried) system, which is the first method by which the fresh cherries are harvested and sundried as a whole. Generally, farmers harvest selectively red cherries by picking them by hand; however a premature harvest can be sometimes carried out by strip picking for needs of cash and fear of thefts (Jacquet $e t$ al., 2008). After drying the cherries are sold to local collectors "Sabsabis", wholesalers "Akrabis" or cooperatives, which are operating the secondary processing facilities (CFC, 2004). The second method is the wet processing method in which the fresh red cherries are processed in three stages i.e. removals of the pulp and mucilage, fermentation and washing, and drying of parchment coffee (CFC, 2004). The covering period during drying and depth of parchment layer affects the total time required to dry parchment coffee to an optimum moisture level. Solomon and Behailu (2006) identified parchment coffee dried at the highest drying depth $(5 \mathrm{~cm})$ gave the lowest value of cup quality, while the other drying depths $(2,3$ and $4 \mathrm{~cm})$ gave better values of cup quality. Then, parchment coffee is dried and ready for transport to where it is sold in the auctions (still in parchment form).

Concerning its marketing, as all Ethiopian coffee, Jimma export coffee has to be channeled through the central auctions in Addis Ababa (CFC, 2004). In washed coffee production, final quality among others is greatly dependent upon the fermentation process (Woelore, 1993). It has been confirmed that under-water soaking following 'dry' fermentation, i.e., two-stage fermentation enhances the appearance of both raw and roast coffees compared to 'dry' fermentation only (Behailu et al., 2008). According to their report post fermentation soaking for 24 hours produced better raw and roast appearance than either 8 or 16 hours soaking but extending the soak to 48 hours did not cause any further improvement to the raw and actually reduced the roast quality. On the other hand, Brownbridge and Michael (1971) have reported that the method of removing the mucilage (dry fermentation, under water fermentation, peptic enzyme accelerated fermentation or chemical cleaning) has no effect on the liquor quality and there is no evidence that any one method can produce significantly better liquors than another. The authors also indicated that high levels of coffee skins in fermenting coffee produces inferior raw, roast and liquor qualities compared to skin-free controls, with the liquors adversely affected by the development of off-flavors variously described as coarse, bitter, fruity, or unclean.

Natural fermentation of coffee is the function of many parameters, such as environmental, $\mathrm{PH}$, temperature, micro flora and level of pollution in the water used, variety difference in the ripe cherries used for pulping, its geographical and cultural origin, the standard of picking and minor variations in the processing method (Behailu et al., 2008). Furthermore, Behailu and Solomon (2006) reported that coffee fermented under shade takes more time, shaded fermentation tanks help to achieve uniform 
fermentation process and better quality coffee than unshaded one. However, assessment made on wet-processed Jimma coffee by Brownbridge and Eyassu (1968) revealed that it is very heterogeneous, containing beans of all shapes, sizes and plain liquor, probably because of such a mixture types characterized by small beans of a nice green color and exquisite aroma. As the authors reported neither plant neither genetics nor the environment can be modified, but effort should be concentrated on the very critical post-harvest practices such as harvesting, processing, drying, storing and transporting of coffee cherries, which are liable to be a major influence components of the quality of the cup. Length and condition of bean storage also affect cup quality (Yigzaw, 2005). Long time storage under high relative humidity and warm conditions increase bean moisture content and consequently reduce quality in terms of raw and roasted appearance as well as liquor (Woelore, 1995).

\subsection{Genetic Factors}

As harvesting method, post- harvest procedures and the physiology of the plant itself affect coffee quality, its genetic origin (species and genotype) also greatly influence coffee quality (Leroy et al., 2006). Agwanda (1999) compared four traits (acidity, body, and flavor) and overall standard for their suitability as selection criteria for the genetic improvement of overall liquor quality. According to the author, based on correlation, repeatability and sensitivity analysis, flavor rating was recommended as the best selection criterion for genetic improvement of cup quality in Arabica coffee. The trait showed high genetic correlation with preference, was easy to determine organoleptically and had relatively high sensitivity in discriminating different coffee genotypes. The study of Yigzaw (2005) also revealed that coffee quality depends on genetic make-up and genes control the production of chemical compounds that behave as aroma agents either directly or as aroma precursors expressed during the roasting process. Hence while selecting a cultivar to be planted; cup quality must be the first priority to be considered (Yigzaw (2005).

Furthermore, Owuor (1988) and Moreno et al. (1995) improved the cup quality of different coffee genotypes with the assistance of professional coffee tasters. Both researchers observed close similarity among liquorersin ranking various cup quality characteristics of the cultivars, indicating that any one panel could be relied on selection for cup quality. Similarly, Agwanda et al. (2003) reported significant genotype $\mathrm{x}$ environment interaction effects on coffee bean and liquor quality. Walyaro (1983) reported relatively lower genotype x environment interaction effects on quality characters.

On the contrary, Van der Vossen (1985) reported non-significant genotype x environment interaction effects on quality characters, such as bean size and cup quality. Selvakumarand Sreenivasan (1989) observed coffee cup quality variation ranging from good to excellent among 54 Arabica coffee accessions collected from Kaffa, Ethiopia. The genotype is a key factor, since it determines to a great extent important characteristics such as the size and shape of the beans as well as their color, chemical composition and flavor (Wintgens, 2004). The shape and structure of beans (elephant, pea bean and empty beans) are the result of both genotype and environmental factors (Wintgens, 2004).

\section{CONCLUSION}

Ethiopia is the center of origin and genetic diversity of Arabica coffee, which provides immense opportunity for the improvement of the crop. Despite the available high genetic diversity and wide ranges of agro-ecologies under which coffee grows in Ethiopia, productivity and quality is lower than many other countries. Apart from low productivity and quality, currently, the Ethiopian coffee industry is facing a number of other challenges or constraints. This review created better understanding of the different factors in which coffee yield quality was reduced in local international markets. It also stressed on some agronomic practices and post-harvest management is important in minimizing the quality aspects or problems of coffee in the farmers' production areas. Whereas, an integrated approach of improving coffee quality and management of agronomic practice, with appropriate marketing has serve both conservation and livelihood development. These facts will support the future trials of best quality production and productivity of coffee.

Future emphasis should be given to due concern for the development of appropriate management practices on the factors which affect coffee quality. Further research was required on the improvement of coffee quality, especially on pre and post-harvest management. Also training of farmers and extension agents on the management of coffee quality and supporting by research activities was paramount important for the continuous supply and quality production and productivity improvement. 


\section{REFERENCES}

[1] AlemayehuTeshome, EsayasKebede and KassuKebede. 2008. Coffee Development and Marketing Improvement Plan. In: Proceedings of A National Work Shop Four Decades of Coffee Research and Development in Ethiopia. 14-17 August 2007, EIAR, Addis Ababa, Ethiopia. pp. 375-381.

[2] Bayetta B (2001) Arabica coffee breeding for yield and resistance to coffee berry disease (Colletotrichumkahawaesp.nov.).Doctoral Dissertation.Imperial College at Wye University of London. UK. pp. 272

[3] Berhanu, T., 2017.Ethiopian coffee sector strategy and prospects, Addis Ababa, Ethiopia. Availableat: <https://afca.coffee/conference/wpcontent/uploads/presentations/2017/d1/Bir

[4] Berthaud J and A Charrier, 1988.Genetic resources of Coffea.pp: 1-42. In: Clarke RJ, Macrae R (eds), Coffee: Agronomy, vol. IV, Elsevier Applied Science, London

[5] Central statistical Agency Agricultural sample survey, 2017 Addis Ababa.

[6] DamanuTullu. 2008. Coffee production and marketing in Oromia Regional State. In: Proceedings of a National Work Shop Four Decades of Coffee Research and Development in Ethiopia. 14-17 August 2007, EIAR, Addis Ababa, Ethiopia. pp. 382-389.

[7] Davis, A., Justin, M., Jenny, W., Susana, B., Timothy, W, Tadesse, W., Zeleke, K., Sebsebe, D.,2017. Effect of climate change on Arabica coffee specie in Ethiopia.

[8] EndaleTaye, T Kufa, ANestre, T Shimber, A Yilma and T Ayano, 2008. Research on coffee field management. In: G Adugna, B Belachew, T Shimber, E Taye and T Kufa (eds.). Coffee Diversity and Knowledge.Proceedings of a national workshop four decades of coffee research and development in Ethiopia, 14-17 August 2007, Addis Ababa, Ethiopia.pp: 187-195.

[9] ICO, 2014.Coffee Production Data. Www.ico.org. Accessed on June 15, 2017: International Coffee Organization.

[10] ITC, 2011. Ethiopian Coffee Quality Improvement Project: 2011 Aid for Trade Global Review: Case Story. International Trade Center (ITC), Geneva, Switzerland.

[11] Kalyan ,2017. Definition of product quality. http://r.search.yahoo.com/_ylt=AwrB8qB5M8xZTQ4A2 QujzbkF;ylu=X3oDMTBtdXBkbHJyBHNlYwNmcC1hdHRyaWIEc2xrA3J1cmw/RV=2/RE=1506583545 $/ \mathrm{RO}=11 / \mathrm{RU}=\mathrm{http} \% 3 \mathrm{a} \% 2 \mathrm{f} \% 2 \mathrm{fkalyancity.blogspot.com} \% 2 \mathrm{f} 2013 \% 2 \mathrm{f} 05 \% 2 \mathrm{fwh}$ at-is-product-quality definition. html/RK=1/RS=KKrxl5qMxWPWWEcmxiTYiizJwkA. [Accessed on 28/09/2017].

[12] Kassaye, T.,2017. Biophysical controls on speciality coffee quality in Jimma zone. Jimma University, and Supporting the development of Commercial Agriculture Programs at four Ethiopian universities (ETH 019), Q-Point The Netherland.

[13] Kufa T, Burkhardt J (2011). Stomatal characteristics in Arabica Coffee Germplasm Accessions under contrasting environments at Jimma, Southwestern Ethiopia International Journal of Botany 7 (1): 63-72.

[14] Leroy, T. Ribeyre, F. Bertrand, B. Charmetant, P. Dufour, M. Montagnon, C. Marraccini, P. and Pot, D. 2006. Genetics of coffee quality.Braz. J. Plant Physiol. 18 (1): 229-242.

[15] Musebe R, Agwenanda C, Mitiku M (2007). Primary coffee processing in Ethiopia: patterns, constraints and determinants. Afr. Crop Sci. Conference Proceed. 8:1417-1421.

[16] TayeKufa, 2010. Environmental Sustainability and Coffee Diversity in Africa

[17] USDA (United States Department of Agriculture),2016. Coffee Production and Exports Remain Steady Report number ET 1615, Ethiopia.

[18] Wintgens, J.N. 2004. Coffee: Growing, Processing, Sustainable Production. A guide book for growers, processors, traders and researchers. Weinheim.

[19] Zewdu, Y., 2016. Explaining The Determinants of Ethiopia's Coffee Export Performance and Potential.Ethiopian Coffee Exporters' Association.

Citation: H. Deribe, "Review on Factors which Affect Coffee (Coffea Arabica L.) Quality in Southwestern, Ethiopia", International Journal of Forestry and Horticulture (IJFH), vol. 5, no. 1, pp. 12-19, 2019. Available: DOI: http://dx.doi.org/10.20431/2454-9487.0501003

Copyright: (c) 2019 Authors. This is an open-access article distributed under the terms of the Creative Commons Attribution License, which permits unrestricted use, distribution, and reproduction in any medium, provided the original author and source are credited. 